\title{
Some Numbers behind Canada's Decision to Adopt an Orphan Drug Policy: US Orphan Drug Approvals in Canada, 1997-2012
}

\begin{abstract}
Quelques chiffres derrière la décision du Canada d'adopter une politique sur les médicaments orphelins : approbations pour les médicaments orphelins des États-Unis, 1997-2012
\end{abstract}

\author{
तु \\ MATTHEW HERDER, JSM, LLM \\ Associate Professor, Faculties of Medicine and Law, Health Law Institute \\ Dalhousie University \\ Halifax, NS \\ TIMOTHY MARK KRAHN, MA \\ Research Associate, Faculty of Medicine, Novel Tech Ethics \\ Dalhousie University \\ Halifax, NS
}

\begin{abstract}
We examined whether access to US-approved orphan drugs in Canada has changed between 1997 (when Canada chose not to adopt an orphan drug policy) and 2012 (when Canada reversed its policy decision). Specifically, we looked at two dimensions of access to US-approved orphan drugs in Canada: (1) regulatory access; and (2) temporal access. Whereas only $63 \%$ of US-approved orphan drugs were granted regulatory approval in 1997, we found that regulatory access to US-approved orphan drugs in Canada increased to $74 \%$ between 1997 and 2012. However, temporal access to orphan drugs is slower in Canada: in a head-on comparison of 40 matched drugs, only two were submitted and four were approved first in Canada; moreover, the mean review time in Canada (423 days) was longer than that in the US (mean $=341$ days), a statistically significant difference $(t[39]=2.04, p=0.048)$. These results raise questions about what motivated Canada's apparent shift in orphan drug policy.
\end{abstract}


Some Numbers behind Canada's Decision to Adopt an Orphan Drug Policy: US Orphan Drug Approvals in Canada, 1997-2012

\section{Résumé}

Nous avons examiné dans quelle mesure l'accès aux médicaments orphelins des États-Unis s'est transformé, au Canada, entre 1997 (alors que le Canada décidait de ne pas adopter une politique sur les médicaments orphelins) et 2012 (tandis que le Canada décidait de renverser sa décision sur la politique). Plus précisément, nous avons examiné deux aspects de l'accès aux médicaments orphelins des États-Unis approuvés au Canada : (1) l'accès réglementaire et (2) l'accès temporel. Bien que seulement 63 \% des médicaments orphelins des États-Unis approuvés avaient reçu l'approbation pour un accès réglementaire en 1997, nous avons observé que l'accès réglementaire aux médicaments orphelins des États-Unis au Canada a augmenté de 74 \% entre 1997 et 2012. Cependant, l'accès temporel aux médicaments orphelins est plus lent au Canada : une comparaison de 40 médicaments appariés a permis d'observer que seulement deux médicaments ont été soumis et quatre ont reçu l'approbation au Canada en premier; de plus, le temps moyen de l'évaluation au Canada (423 jours) était plus long que celui aux États-Unis (moyenne $=341$ jours), une différence statistiquement significative $(t[39]=2.04, p=0.048)$. Ces résultats soulèvent des questions sur ce qui a motivé ce changement apparent de politique sur les médicaments orphelins au Canada.

\section{Introduction}

The term "orphan drug" is generally used to refer to pharmaceutical interventions that target one or more rare diseases. The threshold of rarity varies by jurisdiction; more recent orphan drug policies have utilized incidence-based definitions of rare disease (e.g., disease occurring in five or fewer persons per 10,000) (Herder 2013; Panju and Bell 2010). The term orphan drug can also encompass drugs targeting more prevalent diseases for which research and development (R\&D) is considered commercially unviable, for instance, because a disease disproportionately affects an impoverished population. But since the US first enacted its Orphan Drug Act in 1983 and other jurisdictions followed suit, very few orphan drugs targeting such "neglected diseases" have been developed. In contrast, hundreds of orphan drugs geared towards rare diseases have been approved for sale (Herder 2013).

In 1997, Canada's drug regulator determined that there was no need for an orphan drug policy. In 2012, Canada's Minister of Health reversed that decision, announcing plans to develop an "orphan drug framework" (Health Canada 2012a). What precisely lies behind this policy shift is not known, but several factors are likely in play. First, the pharmaceutical industry's interest in developing drugs for rare diseases is clearly greater now than it was in the late 1990s; such orphan drugs account for an increasing proportion of all drugs approved by the US Food and Drug Administration (FDA) (Coté et al. 2010; Wellman-Labadie and Zhou 2010). Second, the Canadian Organization for Rare Disorders (CORD) came to increasing prominence in the early 2000s, urging federal policy reform (Embrett 2014). Third, Health Canada has an interest in harmonizing its regulatory policies with other influential jurisdictions owing to expectations from industry as well as pressure from its main trading partners in the US and Europe (Lexchin 2012a). What is not known is whether access to US-approved orphan drugs in Canada, measured in terms of the number and timing of regulatory approvals, changed between 1997 and 2012 when Canada changed policy directions. 


\section{Policy context}

The US Orphan Drug Act of 1983 created a specialized regulatory pathway for therapeutic drugs targeting diseases that occur in 200,000 or fewer persons in the US, and established a variety of market-based incentives (e.g., tax credits, seven-year market exclusivity upon regulatory approval) to encourage orphan drug R\&D. Several other jurisdictions have followed suit, including Japan (1993), Australia (1997) and Europe (2000). The precise details differ across jurisdictions. But the US-led, two-part model of a specialized regulatory pathway plus market-based incentives has been consistently emulated on the strength of the assumption that such a model will spur orphan drug R\&D (Herder 2013).

In 1996-1997, Health Canada's Food and Drugs Directorate assessed whether an orphan drug policy was needed in Canada (Health Canada 1997). The Directorate examined whether the orphan drugs that had been approved by the US regulator (the FDA) since the adoption of the Orphan Drug Act in 1983, had also been approved for sale in Canada (albeit without a formal orphan drug designation). The Directorate determined that a clear majority of the US-approved orphan drugs were also available in Canada. In total, $63 \%$ of all of the orphan drugs approved between 1983 and 1997 in the US had also been approved in Canada. And, of the remaining US-approved orphan drugs that had not yet received Canadian approval, most were available through the "Emergency Drug Release Program" - a program that was shortly thereafter replaced by the "Special Access Program" (which still exists today). Those programs allow physicians to apply, on a case-by-case basis, for access to unapproved drugs in order to address the needs of patients who have exhausted available treatment options (Health Canada 1997).

Although the drugs approved in Canada did not always "correspond with the indication for which the drug received its Orphan Drug designation in the US," (Health Canada 1996: 17-18), the Directorate noted that medical "practitioners involved in the treatment of patients with rare diseases are aware of research in their area of expertise" and thus are able to prescribe drugs approved for use in Canada for unapproved orphan indications (Health Canada 1996: 18). In this regard, off-label prescribing is reported as widely used by Canadian medical practitioners in treating rare diseases (SSCSAST et al. 2014).

Finally, the Directorate argued that its priority review program and (then proposed) conditional licensing program (later implemented in 1998) provided two mechanisms "for faster access to drugs, including [o]rphan [d]rugs, which treat life threatening conditions for which no other therapy exists" (1996: 18). Given the availability of US-approved orphan drugs in Canada and these existing mechanisms to spur orphan drug R\&D, the Directorate recommended:

That there be no change to the Food and Drugs Act or its Regulations to accommodate an Orphan Drug policy. Canadians already have access to drugs which have received an Orphan Drug designation and marketing approval in the U.S. through the normal drug approval process [the Emergency Drug Release Program]/[Special Access Program], or potentially through the conditional [Notice of Compliance] initiative. (Health Canada 1996) 
Some Numbers behind Canada's Decision to Adopt an Orphan Drug Policy: US Orphan Drug Approvals in Canada, 1997-2012

The Directorate's analysis apparently proved persuasive. No orphan drug policy or changes to Canadian law were made.

The 1997 decision not to follow the US policy lead was, however, met with strong criticism from rare disease patients. By 2000, the CORD (originally formed in 1996) had brought 150 small rare disease associations together under its umbrella (Embrett 2014). CORD gained increasing profile through the 2000s and advocated strongly for policy change at the federal, as well as provincial/ territorial levels of government. For several years, however, federal policy makers remained silent.

\section{Policy change}

To CORD's relief (Wong-Rieger 2013: 20), in October 2012, the federal government announced plans for an orphan drug framework. A 2012 "Initial Draft Discussion Document" produced by Health Canada's Office of Legislative and Regulatory Modernization (OLRM) soon surfaced online (OLRM 2012). The Discussion Document explains that the objective of the "new" proposal" is to establish a comprehensive framework that will provide access to orphan drugs for Canadians without compromising patient safety (OLRM 2012: 4), and outlines some of the framework's potential parameters. First, the Discussion Document suggested that in order to qualify as an orphan drug, the drug must:

- [be] intended for the diagnosis, treatment, mitigation or prevention of a life-threatening, seriously debilitating, or serious and chronic disease or condition affecting not more than 5 in 10,000 persons in Canada; and

- not [be] currently authorized by the Minister or if currently authorized, it will provide a potentially substantial benefit for the patient distinguishable from the existing therapy (OLRM 2012).

Second, the Discussion Document noted that while a number of incentives would, by virtue of the above definition, be available to orphan drugs, including expedited reviews and data exclusivity for "innovative therapies," no additional market exclusivity akin to the specialized exclusivity for orphan drug indications provided in other jurisdictions would be put into place as part of Canada's orphan drug framework.

However, more than three years after the framework was announced, Health Canada has yet to share any concrete details. Health Canada has stated that it will implement the orphan drug framework by creating a new division in the Food and Drug Regulations specifically focused on orphan drugs (personal communication with MH). With the passage of Bill C-17 in November 2014 - a key piece of patient safety legislation that includes a number of provisions that could be important in the orphan drug context - those new regulations are anticipated soon.

In the meantime, in this paper, we seek to explore what motivated the policy change in favour of a Canadian orphan drug framework. Specifically, we assess whether Health Canada's stated rationale for not pursuing an orphan drug policy in 1997 still held in 2012. No mention of Health Canada's 1997 policy analysis or countervailing data was included in the 2012 announcement; our research here is intended to fill in this gap. 


\section{Methods}

We carried out a retrospective comparison between orphan drugs approved by the FDA during the period 1997-2012 and market authorizations of the same drugs (although not designated as orphan drugs per se) by Health Canada.

Our retrospective comparison was based primarily on publicly available information obtained from the websites of the FDA and Health Canada. We began by searching the FDA website page for orphan drug designations and approvals. Limiting our search to 1997-2012 and setting the search results to "Only approved products", we retrieved the records of all US orphan drug approvals along with key information related to each drug, including orphan drug designation date, approval date, orphan drug designation(s), generic drug name and drug trade-name. Many orphan drugs were approved for multiple orphan drug indications during the time frame under investigation.

A research assistant (a professional pharmacist) then went to the "Health Canada Drug Products Notice of Compliance (NOC) Online Query" website and searched for each unique US-approved orphan drug (using the FDA-generated generic name as the search term for "Medicinal Ingredient") in the Health Canada NOC database. If a drug with the same generic name had been approved by Health Canada, the NOC database yielded similar information as the FDA website, including the drug's trade name and Canadian market authorization date. For a subset of drugs approved in Canada and identified through the NOC database, Health Canada's website also provided a hyperlinked "Summary Basis of Decision" (SBD) containing further information about the drug in question. Most importantly, the SBD provided the date upon which the drug's manufacturer formally submitted its drug for review and potential market approval from Health Canada. This enabled us to calculate review times for each drug approved in this subset of drugs.

We repeated this process of searching Health Canada's NOC database for each orphan drug approved by the FDA during 1997-2012. We used the assembled data to develop two points of comparison: (1) regulatory access, i.e., whether the US-approved orphan drugs were granted regulatory approval in Canada and, if so, whether that Canadian approval was for the same orphan indications; and (2) temporal access, i.e., when US-approved orphan drugs also available in Canada were granted regulatory approval by Health Canada, and the length of the time frame in which the Canadian regulatory reviews occurred as compared to the duration of the US review for a subset of 40 drugs with matched orphan indications. The size of this head-on comparison was limited to 40 because Health Canada only creates SBDs for a subset of its regulatory decisions (Health Canada 2012b). In our case, only 33 had an accompanying SBD that made the Canadian submission date publicly available on the Health Canada website. In an effort to expand our head-on comparison, we contacted two researchers who had recently published a study of drug approval times (Shajarizadeh and Hollis 2014). Those researchers obtained submission data by directly contacting Health Canada (and other drug regulators). The researchers shared their submission data with us; however, because their study was not focused specifically on orphan drugs, we were only able to identify seven additional orphan drugs with matched US-Canada indications that we did not already have submission date data for. Figure 1 uses one drug (sorafenib) to illustrate the various dates (i.e., orphan drug designation, date of submission and approval) that we collected for each drug in our sample. 
Some Numbers behind Canada's Decision to Adopt an Orphan Drug Policy: US Orphan Drug Approvals in Canada, 1997-2012

FIGURE 1. Orphan drug designation, submission and approval: the example of sorafenib

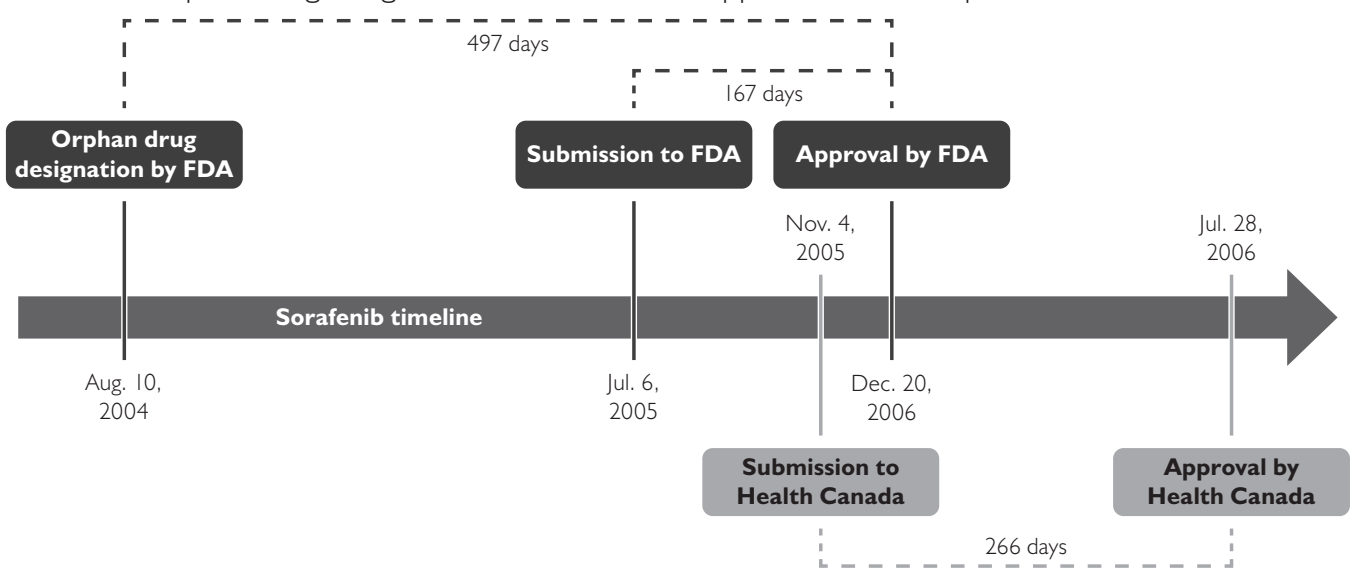

\section{Results}

Regulatory access

Of the 278 orphan drugs approved by the FDA during 1997-2012, 206 (or 74\%) received at least one market authorization in Canada (see Figure 2 for a year-by-year comparison of approvals). The majority of those drugs (150 of 206, or 73\%) were approved for the same indication as the corresponding US orphan drug.

FIGURE 2. Comparing dimensions of regulatory access

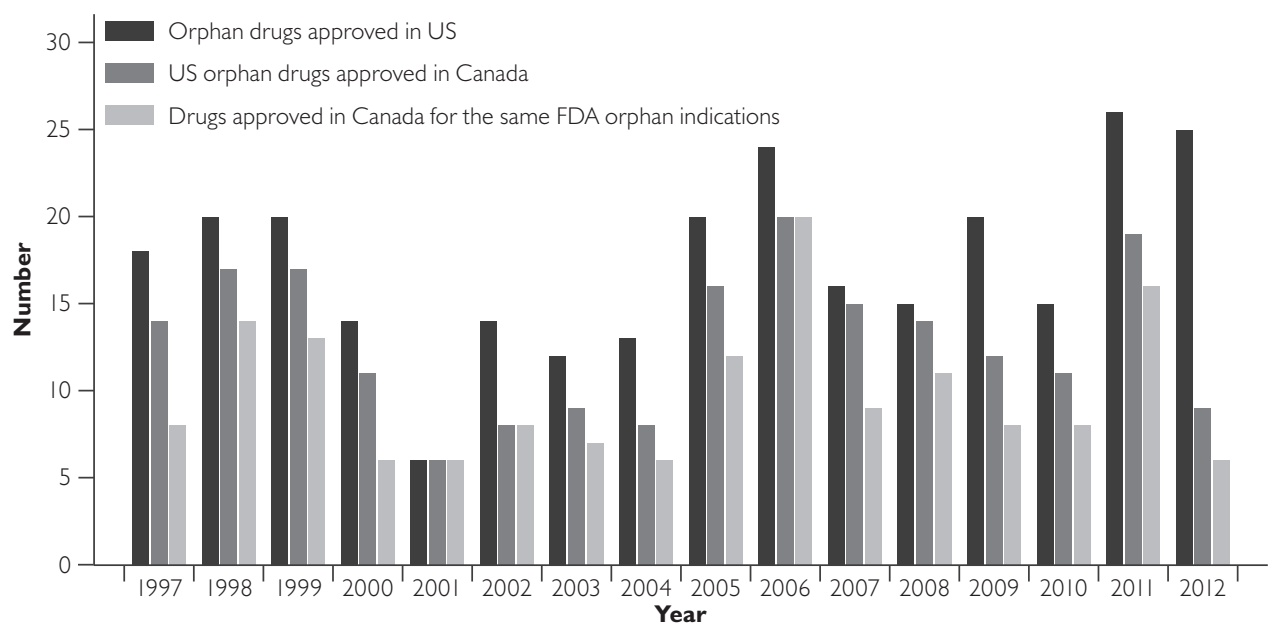

\section{Temporal Access}

We performed a head-on comparison of total days in review before full approval was granted for US-approved orphan drugs versus those same drugs as approved between 1997 and 2012 by Health Canada for the same indications. Consistent with the findings of Shajarizadeh and Hollis (2014), only two drugs in our head-on comparison were submitted to Health Canada prior to being submitted to the FDA. Similarly, only four out of those 40 drugs 
received Canadian regulatory approval before US approval. Thus, delays in access to orphan drugs in Canada were, in part, due to when manufacturers submitted the relevant drugs for regulatory review to Health Canada as compared to when they submitted to the FDA.

Temporal access also depends on the length of regulatory reviews. As shown by Table 1 , Health Canada's review times (i.e., the number of days between submission and approval) are almost always longer than the FDA's for the sample of 40 drugs that we were able to examine. The mean review time for the FDA was 341 days (standard deviation [SD] =259) versus a mean of 423 days $(\mathrm{SD}=219)$ for Health Canada, representing a $19 \%$ faster review rate in the US. This difference of, on average, 82 days between the review times in the two jurisdictions is statistically significant $(t[39]=2.04, p=0.048)$, although only at the $p<0.05$ level. (The seven drugs for which SBDs were not available did not have a statistically different mean review time than the 33 remaining drugs.)

TABLE 1. Comparing dimensions of temporal access. Entries appear in descending order (from oldest to most recent) according to US market approval dates

\begin{tabular}{|c|c|c|c|c|c|c|}
\hline $\begin{array}{l}\text { Generic } \\
\text { name US }\end{array}$ & $\begin{array}{l}\text { Trade name } \\
\text { US }\end{array}$ & $\begin{array}{l}\text { Number of } \\
\text { days from } \\
\text { designation to } \\
\text { approval, US }\end{array}$ & $\begin{array}{l}\text { Number of } \\
\text { days from } \\
\text { submission to } \\
\text { approval, US }\end{array}$ & $\begin{array}{l}\text { Number of days } \\
\text { from submission } \\
\text { to approval, } \\
\text { Canada }\end{array}$ & $\begin{array}{l}\text { Submission } \\
\text { in Canada } \\
\text { first? }\end{array}$ & $\begin{array}{l}\text { Approval } \\
\text { in Canada } \\
\text { first? }\end{array}$ \\
\hline Temozolomide & Temodar & 364 & $458 *$ & 571 & Yes & Yes \\
\hline Nitric oxide & Inomax & 920 & 2,375 & 814 & No & No \\
\hline Imatinib & Gleevec & 72 & $\begin{array}{l}\text { Designated } \\
\text { after approval }\end{array}$ & 202 & No & Yes \\
\hline Bosentan & Tracleer & 368 & 528 & 248 & No & No \\
\hline Oxybate & Xyrem & 887 & 2,928 & 605 & No & No \\
\hline Pegvisomant & Somavert & 823 & ।,735 & 1,005 & No & No \\
\hline Laronidase & Aldurazyme & 278 & 2,044 & 530 & No & No \\
\hline Miglustat & Zavesca & 832 & 1,889 & 217 & No & No \\
\hline $\begin{array}{l}\text { Pemetrexed } \\
\text { disodium }\end{array}$ & Alimta & 128 & 890 & 197 & No & No \\
\hline Cinacalcet & Sensipar & 185 & 94 & 269 & No & No \\
\hline Azacitidine & Vidaza & 145 & 1,164 & 211 & No & No \\
\hline Clofarabine & Clolar & 274 & 910 & 434 & No & No \\
\hline Nelarabine & Arranon & 182 & 385 & 724 & No & No \\
\hline Deferasirox & Exjade & 187 & ।,077 & 481 & No & No \\
\hline Sorafenib & Nexavar & 167 & 497 & 266 & No & No \\
\hline Lenalidomide & Revlimid & 264 & 698 & 339 & No & No \\
\hline $\begin{array}{l}\text { Recombinant } \\
\text { human acid } \\
\text { alpha-glucosidase }\end{array}$ & $\begin{array}{l}\text { 1. Myozyme } \\
\text { 2. Lumizyme }\end{array}$ & 275 & 3,174 & 228 & No & No \\
\hline
\end{tabular}


Some Numbers behind Canada's Decision to Adopt an Orphan Drug Policy: US Orphan Drug Approvals in Canada, 1997-2012

\begin{tabular}{|c|c|c|c|c|c|c|}
\hline $\begin{array}{l}\text { Generic } \\
\text { name US }\end{array}$ & $\begin{array}{l}\text { Trade name } \\
\text { US }\end{array}$ & $\begin{array}{l}\text { Number of } \\
\text { days from } \\
\text { designation to } \\
\text { approval, US }\end{array}$ & $\begin{array}{l}\text { Number of } \\
\text { days from } \\
\text { submission to } \\
\text { approval, US }\end{array}$ & $\begin{array}{l}\text { Number of days } \\
\text { from submission } \\
\text { to approval, } \\
\text { Canada }\end{array}$ & $\begin{array}{l}\text { Submission } \\
\text { in Canada } \\
\text { first? }\end{array}$ & $\begin{array}{l}\text { Approval } \\
\text { in Canada } \\
\text { first? }\end{array}$ \\
\hline Idursulfase & Elaprase & 243 & 1,699 & 211 & No & No \\
\hline Vorinostat & Zolinza & 184 & 934 & 349 & No & No \\
\hline Eculizumab & Soliris & 182 & ।,304 & 215 & No & No \\
\hline Temsirolimus & Torisel & 237 & 895 & 396 & No & No \\
\hline Ambrisentan & Letairis & 184 & 1,065 & 352 & No & No \\
\hline Lanreotide & $\begin{array}{l}\text { Somatuline } \\
\text { Depot }\end{array}$ & 307 & 2,485 & 419 & Yes & Yes \\
\hline Nilotinib & Tasigna & 395 & 550 & 644 & No & No \\
\hline Sapropterin & Kuvan & 202 & $|, 4| 4$ & 274 & No & No \\
\hline Romiplostim & Nplate & 304 & 1,975 & 461 & No & No \\
\hline Rufinamide & Banzel & 1,093 & ।,557 & 351 & No & No \\
\hline Eltrombopag & Promacta & 338 & 199 & 765 & No & No \\
\hline Plerixafor & Mozobil & 182 & 1,896 & 352 & No & No \\
\hline Ofatumumab & Arzerra & 269 & 23 & 413 & No & No \\
\hline Aztreonam & Cayston & 829 & 2,626 & 535 & No & Yes \\
\hline $\begin{array}{l}\text { Velaglucerase- } \\
\text { alfa }\end{array}$ & Vpriv & 179 & 204 & 345 & No & No \\
\hline Ipilimumab & Yervoy & 273 & 2,575 & 476 & No & No \\
\hline Vemurafenib & Zelboraf & 112 & 240 & 212 & No & No \\
\hline Crizotinib & Xalkori & 149 & 347 & 322 & No & No \\
\hline $\begin{array}{l}\text { Ruxolitinib } \\
\text { phosphate }\end{array}$ & Jakafi & 166 & 1,286 & 203 & No & No \\
\hline Ivacaftor & Kalydeco & 105 & 1,862 & 210 & No & No \\
\hline
\end{tabular}

*The path to regulatory approval is subject to vary. In most cases, drugs are designated as orphan drugs long before a formal submission for regulatory review is made. However, in other cases, the drug will have been submitted for one indication (a non-orphan disease), but then the indication will be changed to that of a rare disease, or such an indication will be added. In this way, a drug may receive an orphan designation after submission.

It is important to note that the time lag between when a drug is designated by the FDA as an orphan drug and the date of market approval is substantially longer (mean =1,285 days; $\mathrm{SD}=881$ ) than the average review time in the US of 341 days. Manufacturers often sponsor further studies of a drug after receiving an orphan drug designation before the evidence is submitted to the regulator. As a result, orphan drugs are typically in the US system (i.e., from the time of designation as an orphan drug through to market approval) approximately three times as long as the period of review, from submission to approval, in Canada. It stands to reason that if Canada were to follow the US model and adopt a regulatory pathway, specifically for drugs targeting rare diseases as orphan 
drugs, this might serve to expedite the review process from submission to approval in Canada. However, this would often occur only after a considerable period of back and forth between the regulator and manufacturer over the orphan drug designation and the evidence required for submission on the front end of that review.

\section{Discussion}

\section{Interpretation of key findings}

By Health Canada's estimate, 63\% of orphan drugs approved in the US by 1997 were available in Canada at that time; in contrast, our findings demonstrate that this percentage of regulatory access grew to 74\% during 1997-2012. Although a sizeable number of these approvals (56 of 206) were not for the same orphan indication approved by the FDA, as in 1997, Canadian medical practitioners still have the ability to prescribe such drugs off-label to treat the rare diseases in question, at least in instances where the drug's dosage could be adjusted without unduly compromising patient safety or prescription adherence. This finding suggests that the rationale the government invoked to decide against enacting an orphan drug policy in 1997 still held when it reversed its position in 2012.

It is plausible that the timing of drug approvals lies behind the federal government's decision in 2012 to develop an orphan drug policy. Indeed, nearly all of the drugs we examined entered the Canadian market after the US market. Thus, there is likely pressure to harmonize Canada's regulatory framework with that of other major jurisdictions, most notably the US and Europe. Health Canada officials stated at a CORD meeting held in late 2013 that, once Canada's orphan drug regulations are in place, manufacturers will be able to electronically submit essentially the same package for review as that which is submitted to the FDA. In theory, this will position Health Canada to review the file in lock-step with the FDA, and make a decision about market approval within roughly the same time frame. Therefore, the goal of making it simpler for companies to file a submission to Health Canada creates an incentive to mirror the US orphan drug policy.

However, our findings complicate this rationale. We found a significant difference not just for when drugs were approved in the US versus Canada, but also in terms of how long reviews took in the US versus Canada. In our sub-sample of 40 US-approved orphan drugs that were approved for the same indication in Canada and for which the submission date data were available, review-for-approval times were 19\% faster in the US than in Canada. This suggests that achieving comparable temporal access to orphan drugs may be more complex than facilitating submission of a drug file to Health Canada contemporaneously with submission to the FDA. Health Canada does not have the same resources at its disposal as the FDA. Unless Health Canada intends to simply rubber stamp FDA approvals, there is no guarantee that decisions will be made simultaneously.

Moreover, aiming to synchronize orphan drug approvals with the FDA discounts the potential advantages of delayed market entry in terms of patient safety. We suspect that the longer average review times we observed for the 40 drugs in our comparative sub-sample were due not only to differences in terms of its available institutional resources, but also to the fact that more safety and effectiveness data flowing from use of the drug in the US would have been part of the package 
Some Numbers behind Canada's Decision to Adopt an Orphan Drug Policy: US Orphan Drug Approvals in Canada, 1997-2012

submitted to Health Canada. Within our sample, it should be noted that Health Canada issued a number of notices of non-compliance and deficiency notices owing to a variety of quality, safety and efficacy issues. More specifically, for the 33 drugs with SBDs available, Health Canada issued:

1. seven screening deficiency notices;

2. six notices of non-compliance, including concerns related to quality, safety and efficacy and adequate communication of risks; and

3. two notices of deficiency, citing safety issues.

It is plausible that these issues noted in the SBDs explain the longer review times we observed with Health Canada.

While rare disease patients desire timely access to orphan drugs, knowledge about the safety and effectiveness of such drugs tends to be limited at the time of market approval. Owing to the small number of patients afflicted with a given rare disease, "alternative trial designs" (e.g., lacking randomization and blinding) are frequently employed in pre-market studies, which "can lead to identifying benefits that are not real or missing risks that are" (Kesselheim and Avorn 2011: 1546). In addition, drugs that address unmet patient needs, which orphan drugs should target almost by definition, are usually fast-tracked through review by regulators. Yet fast-tracked drugs have been shown to have a significantly higher incidence of post-market safety warnings than regularly reviewed drugs (Graham and Nuttall 2013; Lexchin 2012b). Accordingly, attempting to parallel FDA decision-making in real time may cut out from the review process access to added safety and effectiveness information that Canadian rare disease patients might otherwise benefit from.

\section{Limitations}

There are three main limitations to our study. First, a significant percentage of orphan drug access in Canada depends on physicians' ability to prescribe off-label. Little information about the extent of such off-label prescribing is currently available in Canada; more knowledge about off-label prescribing is needed to understand the level of access to rare disease therapies. Second, our comparison of temporal access to orphan drugs was limited to a relatively small number of drugs $(n=40)$ for the reasons stated above. Third, Health Canada's assessments referenced by the federal government's policy decision against adopting an orphan drug policy in 1997 did not include information about comparative timely access to US-approved orphan drugs between the two jurisdictions up until that point of time. Thus our analysis of this dimension is limited to inter-regulatory comparisons for the time period of 1997-2012 and does not include intra-regulatory comparisons between Health Canada's average review times of US-approved orphan drugs up to 1997 versus after 1997 up to 2012.

\section{Conclusion}

We have attempted to measure access to US-approved orphan drugs in Canada in terms of the number and timing of regulatory approvals by Health Canada for the period of 
1997-2012. On the one hand, regulatory access seems to have moderately improved since 1997. On the other hand, temporal access remains a challenge in Canada. In a subset of drugs approved for the same orphan indication(s) in both jurisdictions, most of these drugs received regulatory approval in the US before Canada, and review times were, on average, longer in Canada. This could be a contributing factor to Canada's shift towards an orphan drug policy in 2012 .

However, we suspect that other factors, including a desire to harmonize regulatory pathways with US and European regulators (which have orphan drug laws in place), industry's steadily increasing interest in developing orphan drugs, and the influence of patient groups such as CORD, were more salient in Canada's policy shift in the orphan drug arena. Even though relevant regulatory access may have improved since 1997, stakeholder expectations for what counts as an acceptable threshold for access has changed and/or stakeholders have become more effective in having this recognized by government. A recent paper underscores the influential role that CORD played in Canada's policy-making process (Embrett 2014). These factors were beyond the scope of our study, but we believe that CORD's role, influence and practices merit further study, particularly as Health Canada starts to integrate patients directly into its regulatory review process - a move currently being piloted with two rare disease treatments undergoing review (Health Canada 2014). While policy making is never just an evidence-based exercise, it is troubling that there is no indication that evidence, whether an updated picture of the number and timing of US-approved orphan drugs granted regulatory approval in Canada, or the growing body of scholarship documenting the trade-offs involved in copying the US's orphan drug policy, informed Canada's shift in policy.

\section{Acknowledgements}

This research was supported by grant funding from Genome Canada as part of a larger research project called "IGNITE." Some support was also received through the Canada Research Chair in Bioethics and Philosophy on "Impact Ethics: Making a Difference" (http://bit.ly/ X6YKO2) awarded to Françoise Baylis. Without the research assistance of Katrina Grentz, this research would not have been possible. The authors would also like to thank members of the Novel Tech Ethics research group at Dalhousie University for their feedback on a draft of this paper. The authors declare that they have no competing or conflicting interests.

Correspondence may be directed to: Matthew Herder, JSM, LLM, Associate Professor, Faculties of Medicine and Law, Health Law Institute, Dalhousie University, Halifax, NS; e-mail: Matthew.Herder@Dal.ca. 


\section{Some Numbers behind Canada's Decision to Adopt an Orphan Drug Policy: US Orphan Drug Approvals in Canada, 1997-2012}

\section{References}

Coté, T.R., K. Xu and A.R. Pariser. 2010. “Accelerating Orphan Drug Development." Nature Reviews Drug Discovery 9(12): 901-02.

Embrett, M.G. 2014. “Examining Why the Canadian Federal Government Placed an Orphan Drug Strategy on Their Decision Agenda Now." Health Reform Observer/Observatoire des réformes de santé 2: 1-10.

Graham, J.E. and R.K. Nuttall. 2013. “Faster Access to New Drugs: Fault Lines between Health Canada's Regulatory Intent and Industry Innovation Practices." Ethics in Biology, Engineering and Medicine: An International Journal 4(3): 231-39.

Health Canada. 1996. Orphan Drug Policy (961127.INT). Food and Drugs Directorate, Government of Canada.

Health Canada. 1997. Policy Issues: Orphan Drug Policy. Correspondence. Food and Drugs Directorate, Government of Canada. Retrieved January 16, 1997.

Health Canada. 2012a. An Orphan Drug Framework for Canada. Government of Canada. Retrieved 2 December, 2013. <www.hc-sc.gc.ca/ahc-asc/media/nr-cp/_2012/2012-147a-eng.php>. On file with authors.

Health Canada. 2012b. Frequently Asked Questions: Summary Basis of Decision (SBD) Project: Phase II [Frequently Asked Questions]. Government of Canada. Retrieved 15 April, 2016. <http://www.hc-sc.gc.ca/dhp-mps/ prodpharma/sbd-smd/sbd_qa_smd_fq-eng.php $>$.

Health Canada. 2014. "Canada News Centre - Minister Ambrose Announces Patient Involvement Pilot for Orphan Drugs [News Releases].” Government of Canada. Retrieved 15 April, 2016. <http://news.gc.ca/web/ article-en.do?nid $=873619>$.

Herder, M. 2013. "When Everyone Is an Orphan: Against Adopting a U.S.-Styled Orphan Drug Policy in Canada." Accounts of Chemical Research 20(4): 227-69.

Kesselheim, A.S. and J. Avorn. 2011. "Clinical Trials of Orphan Drugs for Cancer-Reply." JAMA: The Journal of the American Medical Association 306(14): 1545-46. doi:10.1001/jama.2011.1464.

Lexchin, J. 2012a. “Harmony in Drug Regulation, but Who's Calling the Tune? An Examination of Regulatory Harmonization in Health Canada." International Journal of Health Services 42(1): 119-36.

Lexchin, J. 2012b. "New Drugs and Safety: What Happened to New Active Substances Approved in Canada between 1995 and 2010?" Archives of Internal Medicine 172(21): 1680-81.

Office of Legislative and Regulatory Modernization (OLRM). 2012. Initial Draft Discussion Document for a Canadian Orphan Drug Regulatory Framework. Retrieved 15 April, 2016. <http://www.orpha.net/national/ data/CA-EN/www/uploads/Initial-Draft-Discussion-Document-for-A-Canadian-Orphan-Drug--RegulatoryFramework.doc $>$.

Panju, A.H. and C.M. Bell. 2010. "Policy Alternatives for Treatments for Rare Diseases." Canadian Medical Association Journal 182(17): E787-92.

Shajarizadeh, A. and A. Hollis. 2014. "Delays in the Submission of New Drugs in Canada." Canadian Medical Association Journal 187(1): E47-51.

SSCSAST, K. Ogilvie and A. Eggleton. 2014. Prescription Pharmaceuticals in Canada: Off-Label Use. Standing Senate Committee on Social Affairs, Science and Technology. Retrieved 15 April, 2016. <www.parl.gc.ca/ Content/SEN/Committee/412/soci/rep/rep05jan14-e.pdf>.

Wellman-Labadie, O. and Y. Zhou. 2010. "The US Orphan Drug Act: Rare Disease Research Stimulator or Commercial Opportunity?" Health Policy 95(2/3): 216-28.

Wong-Rieger, D. 2013. “Canada’s Long Journey toward an Orphan Drug Framework.” Advocate 20(2): 20-21. 